Journal of Applied Pharmaceutical Science Vol. 2 (9), pp. 050-053, September, 2012

Available online at http://www.japsonline.com

DOI: $10.7324 /$ JAPS.2012.2910

ISSN 2231-3354 (cc) BY-NC-SA

\title{
Effects of R osiglitazoneand Acarbose (with and without Cornstarch Diet) on Serum Electrolytes in Diabetic Rats
}

\author{
Humera Khatoon $^{1}$ and Rahila Najam ${ }^{2}$ \\ ${ }^{1}$ Assistant Professor, Faculty of Pharmacy, Jinnah University for Women, Karachi, Pakistan \\ ${ }^{2}$ Associate Professor, Department of Pharmacology, Faculty of Pharmacy, University of Karachi, Pakistan
}

\section{ARTICLE INFO}

Article history:

Received on: 17/08/2012

Revised on: 31/08/2012

Accepted on:04/09/2012

Available online: 28/09/2012

Key words: Resistant starch, oral hypoglycemic, cardiac toxicity, serum electrolytes, nephrotoxicity, alphaglucosidase inhibitor.

\begin{abstract}
The purpose of this study is to highlight potential risks associated with the use of oral hypoglycemics as monotherapy in treatment of type 2 diabetes mellitus. For this study 40 Wistar albino rats were equally divided into four groups. Group I served as diabetic control and II, III and IV were treated with acarbose with regular diet, acarbose with cooked cornstarch diet and rosiglitazone respectively. Diabetes was induced with a single dose of alloxan monohydrate IP at a dose of $150 \mathrm{mg} / \mathrm{kg}$ body weight. Drug samples were administered orally for a period of 4 weeks and effects of the drugs were studied on day 7, 15 and 30 for serum level of sodium and potassium. Results showed decrease in sodium and potassium level in all treated groups on day 7. On day 30 levels were increased in group II and IV but decreased significantly in group III. It has been concluded that chronic doses of rosiglitazone and acarbose with regular diet may cause abnormal levels of electrolytes which may cause irregular cardiac contractility. Administration of acarbose with cornstarch diet may be beneficial in regulating cardiac contractility.
\end{abstract}

\section{INTRODUCTION}

Metabolic disturbances in diabetes mellitus are frequently accompanied with electrolyte imbalances and thought to be responsible for the development of neuropathy, nephropathy and vascular diseases. Saito et al. (1999) reported that impaired insulin function in diabetes mellitus results in an inverse relationship between serum sodium and potassium levels which may be based on the movement of electrolytes between intra and extra cellular space. Previous studies showed that chronic use of oral hypoglycemics caused hepatic, renal and cardiovascular effects which prompted us to further investigate the effects of

\footnotetext{
* Corresponding Author

H\# R-71, Etawah Co-operative Housing Society, Scheme \#33, Sector 52/A, Near Gulshan-e-Maymar, Karachi, Postal code 75330, Pakistan. Ph: 00-92-21-03343311760
}

acarbose and rosiglitazone on serum electrolytes. This study was aimed to evaluate the electrolyte homeostasis during the progression of diabetes mellitus and to highlight potential risks associated with prolonged use of acarbose and rosiglitazone as monotherapy in treatment of type 2 diabetes mellitus. In 1986, Glick et al reported that cooked cornstarch diet is very helpful in minimizing GI adverse effects associated with acarbose therapy. In our present study we have evaluated the effects of resistant starch diet in electrolyte homeostasis when administered along with acarbose and compared with rosiglitazone. Acarbose is metabolized within the gastrointestinal tract and is completely excreted by the kidneys. The recommended initial acarbose dose is $25 \mathrm{mg}$ orally t.i.d. with the first bite of each meal. The most common side effects with acarbose therapy are abdominal pain, diarrhea and flatulence and increase in liver enzymes (Hoffmann and Spengler, 1997). 
Rosiglitazone is extensively metabolized in the liver and excreted through kidneys. It may be administered at a starting dose of $4 \mathrm{mg}$ daily. Plasma rosiglitazone concentrations may be significantly increased in patients with pre-existing hepatic impairment (Avandia package insert, 2000).

\section{MATERIALS AND METHODS}

\section{Selection of animal \& treatment}

The present study was carried out on 40 adult albino rats (either sex) of Wistar strain weighing 200-300 gram. Animals bred locally in animal house of Department of Pharmacology, University of Karachi, were used in this study. The animals were housed in iron cages as groups of 3 animals per cage. Before induction of diabetes and administration of drugs the animals were fed on regular rat pellet diet and water ad libitum. One of the groups was fed with cooked cornstarch diet.

Animals were handled as per specifications provided in Helsinki Resolution 1964 and study is approved by our Board of Advanced Studies and Research vide Resol. No. 12(30) dated: 1404-2010.

\section{Induction of diabetes}

To induce diabetes, animals were injected with a single dose of freshly prepared aqueous solution of alloxan monohydrate (intraperitoneally at a dose of $150 \mathrm{mg} / \mathrm{kg}$ body weight ( Rao et al., 2001). Since alloxan is capable of producing total hypoglycemia as a result of massive pancreatic insulin release, the rats were kept for the next 24 hours on 5\% glucose solution orally (Gupta et al., 1984).Controlled rats treated identically and served as diabetic control. After 48 hours, the blood samples were drawn in order to ensure that hyperglycemia has been induced. Blood glucose levels were determined by using a portable glucose analyzer (Abbott Medisense Optium Blood Glucose analyser). The levels of blood glucose considered to be normal ranges from $50-135 \mathrm{mg} / \mathrm{dl}$. Animals with glucose levels $>200 \mathrm{mg} / \mathrm{dl}$ were considered as diabetic and selected for experimental study (Pari and Maheswari, 1999).

\section{Preparation of Diet}

The animals were kept on regular rat pallet diet .Since flatulence, diarrhea and GI distention are major adverse effects associated with acarbose therapy, one of the groups was fed on cooked cornstarch diet to minimize these effects (Glick et al., 1986). Cooked cornstarch diet was prepared by the method described by Miller (1978) in her study using corn starch as a source of carbohydrate and no sugars.

\section{Experimental protocol}

The animals were divided into 4 groups of 10 animals each:

- Group I was alloxan treated (served as diabetic control).

- Group II was acarbose with regular diet treated at a dose of $1.66 \mathrm{mg} / \mathrm{kg} /$ three times a day.
- Group III was acarbose with cooked cornstarch diet treated at a dose of $1.66 \mathrm{mg} / \mathrm{kg} /$ three times a day.

- Group IV was rosiglitazone treated at a dose of $0.034 \mathrm{mg} / \mathrm{kg} /$ twice a day.

The doses of acarbose and rosiglitazone were prepared in distilled water in concentration of $50 \mathrm{mg} / 5 \mathrm{ml}$ and $2 \mathrm{mg} / 2 \mathrm{ml}$ respectively by serial dilution method. The control group animals were given distilled water only. Diabetic rats were subjected to drug treatment on the $2^{\text {nd }}$ day after induction. Drug samples were administered orally for a period of total four weeks. Blood samples were collected from caudal vein of each animal and plasma/serum was separated out by centrifuging the blood samples in Humax 14 $\mathrm{K}$ (Germany) at $3000 \mathrm{RPM}$ for 15 minutes. Effects of drugs on serum electrolytes were monitored on day 7,15 and 30.

\section{Estimation of serum sodium and potassium}

For estimation of serum sodium and potassium samples were sent to Dr. Punjwani Center for Molecular Medicine and Drug Research (PCMD) diagnostic laboratory located in H.E.J Research Institute, University of Karachi within 1 hour after collection.

\section{STATISTICAL ANALYSIS}

Results were expressed as mean \pm SEM. Differences were statistically analyzed by one-way ANOVA, followed by Students-Newman-Keuls post hoc analysis. P- values $<0.005$ were considered statistically significant.

\section{RESULTS AND DISCUSSION}

It has been reported that impaired insulin action as well as hyperosmolality results in abnormalities in the movement of electrolytes between intra and extra cellular space (Saito et al., 1999). Intra and extra cellular cationic homeostasis is regulated by the red cell $\mathrm{Na}+\mathrm{K}+-\mathrm{ATPase}$. Alterations of this transport enzyme are thought to be linked to several complications of diabetes mellitus. Totan and Greaby (2002) reported decreased Na+-K+ATPase activity in diabetic animals in various tissues including erythrocytes. A decrease in this enzyme activity has been implicated in the pathogenesis of diabetes neuropathy, nephropathy and vascular diseases in humans. Recently, Shahid et al. (2005) reported that $\mathrm{Na}+\mathrm{K}+-\mathrm{ATPase}$ dysfunction results in significant increase in serum potassium and calcium levels whereas serum sodium were significantly decreased in diabetic patients.

Results of our present study showed a non significant decrease in serum sodium levels in group IV on day 7 and 15 (table \#1). Potassium levels were also decreased on day 7 then increased $(\mathrm{p}<0.001)$ after 15 days in the same group (table \#2). However, there was a significant rise in sodium $(\mathrm{p}<0.005)$ and potassium levels $(\mathrm{p}<0.001)$ after prolonged administration of rosiglitazone (table \# 1, 2). 
Table. 1: Effect of drugs on serum sodium level.

\begin{tabular}{|c|c|c|c|c|c|c|}
\hline \multirow{3}{*}{ Groups } & \multicolumn{6}{|c|}{ Serum sodium $\mathbf{m E q} / \mathbf{L}$} \\
\hline & \multicolumn{2}{|c|}{ Day 7} & \multicolumn{2}{|c|}{ Day 15} & \multicolumn{2}{|c|}{ Day 30} \\
\hline & Mean \pm S.E & $\mathrm{P}$ & Mean \pm S.E & $\mathrm{P}$ & Mean \pm S.E & $\mathrm{P}$ \\
\hline $\mathrm{I}$ & $145.40 \pm 3.98$ & - & $148.09 \pm 2.84$ & - & $140.90 \pm 3.48$ & - \\
\hline II & $136.80 \pm 3.85$ & 0.0001 & $146.42 \pm 4.24$ & 0.32 & $146.30 \pm 3.33$ & 0.0025 \\
\hline III & $139.00 \pm 4.00$ & 0.0023 & $137.09 \pm 4.29$ & 0.0000 & $135.80 \pm 3.43$ & 0.0042 \\
\hline IV & $141.80 \pm 4.53$ & 0.062 & $147.42 \pm 4.48$ & 0.7 & $145.90 \pm 3.48$ & 0.0048 \\
\hline
\end{tabular}

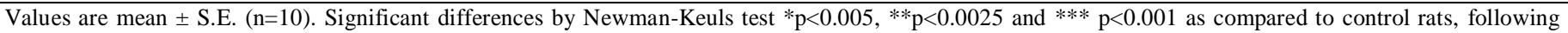
one-way ANOVA df $(3,39)$.

Table. 2: Effect of drugs on serum potassium level.

\begin{tabular}{|c|c|c|c|c|c|c|}
\hline \multirow{3}{*}{ Groups } & \multicolumn{6}{|c|}{ Serum potassium $\mathrm{mEq} / \mathrm{L}$} \\
\hline & \multicolumn{2}{|c|}{ Day 7} & \multicolumn{2}{|c|}{ Day 15} & \multicolumn{2}{|c|}{ Day 30} \\
\hline & Mean \pm S.E & $\mathrm{P}$ & Mean \pm S.E & $\mathrm{P}$ & Mean \pm S.E & $\mathrm{P}$ \\
\hline I & $7.06 \pm 0.45$ & - & $7.06 \pm 0.27$ & - & $6.85 \pm 0.30$ & - \\
\hline II & $5.94 \pm 0.64$ & 0.0004 & $7.19 \pm 0.58$ & 0.52 & $8.99 \pm 0.38$ & 0.0000 \\
\hline III & $6.01 \pm 0.43$ & 0.0001 & $5.67 \pm 0.46$ & 0.0000 & $5.86 \pm 0.32$ & 0.0000 \\
\hline IV & $6.95 \pm 0.42$ & 0.58 & $7.80 \pm 0.29$ & 0.0000 & $7.94 \pm 0.39$ & 0.0000 \\
\hline
\end{tabular}

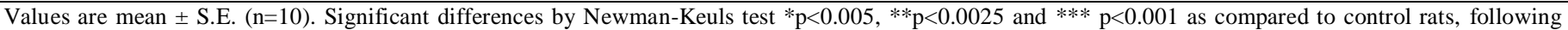
one-way ANOVA df(3,39).

Mechanism which may be involved is explained by Guan et al. (2005) and Zhang et al. (2005) that PPAR- $\gamma$ agonists upregulate the collecting duct sodium channel $(\mathrm{ENaC})$ and stimulate active sodium transport in this nephron segment. The above findings also complemented by the study of Chen et al. (2005) that in the renal medulla PPAR- $\gamma$ agonists increase the expression of the $\mathrm{ENaC}$ as well as transcellular sodium transport such as $\mathrm{Na}, \mathrm{K}$-ATPase. Results of our present study are in accordance to pioneer studies. A consensus statement was published simultaneously in Circulation and Diabetes Care from the American Heart Association and the American Diabetes Association that thiazolidinediones use is associated with fluid retention and thus increases the risk of congestive heart failure in diabetic patients (Nesto et al., 2003) and is characterised by raised cytosolic levels of $\mathrm{Na}+, \mathrm{Na}+\mathrm{K}+$ pump inhibition and diastolic dysfunction. Raised cytosolic levels of $\mathrm{Na}+$ may contribute to removal of cytosolic $\mathrm{Ca}^{2+}$ via $\mathrm{Na}^{+}-\mathrm{Ca}^{2+}$ exchange and hence to diastolic relaxation (Weber and Piacentino ,2003).

In the present study when acarbose was administered with regular diet (Group II) it showed a significantly decreased sodium level ( $\mathrm{p}<0.001)$ on day 7 (table \#1). The level was found to be decreased on day 15 but not significantly and then maintained on the same level $(\mathrm{p} \leq 0.0025)$ on $30^{\text {th }}$ day (table \#1). Significant decrease in the potassium level $(\mathrm{p}<0.001)$ was observed on day 7 in the same group and then increased significantly $(p<0.001)$ on long run (table \#2). The probable mechanism involved being the restored $\mathrm{Na}+\mathrm{K}+-$ ATPase and insulin function.

However, results of acarbose when administered with cornstarch diet (Group III) showed a significant reduction in serum sodium as well as potassium levels. Decrease in sodium level is thought to be due to Na+-K+- ATPase dysfunction, impaired insulin action as well as hyperosmolality (Shahid et al., 2005) as discussed above. Decrease in serum potassium level may be through transport of potassium inside due to better insulin release and glycemic control. This effect need to be further investigated.

\section{CONCLUSION}

The above results suggest that there may be progression in electrolyte abnormalities in diabetes mellitus leading to end stage renal disease along with the abnormality of their chief transport mechanism. It also shows the potentiality of electrolytes disturbances as indicators for the progression of diabetic nephropathy and also beneficial in prognosis and treatment of the disease.

Based on our current findings it has been concluded that treatment of type 2 diabetes mellitus with acarbose is more beneficial when it is administered with cooked cornstarch diet as indicated by significant reduction in serum sodium and potassium levels in group III. Chronic doses of rosiglitazone(group IV) and acarbose (group II) may cause abnormal levels of electrolytes. Increased serum level of potassium with rosiglitazone and acarbose when administered with regular diet may depresses cardiac contractility, automaticity, conductivity and excitability leading to ECG changes, which may not be the beneficial effect of acarbose therapy in type 2 diabetes mellitus. Administration of acarbose with cornstarch diet may be beneficial in regulating cardiac contractility and therefore suggested that other serum electrolytes e.g. magnesium and calcium should also be monitored in diabetic patients when treated with acarbose.

\section{ACKNOWLEDGEMENT}

We sincerely acknowledge Dr. Panjwani Center for Molecular Medicine and Drug Research (PCMD) Diagnostic Laboratory, University of Karachi for providing technical assistance to carry out the biochemical studies.

\section{REFERENCES}

Avandia (rosiglitazone maleate), package insert (2000) Philadelphia, Pa: GlaxoSmithKline Pharmaceuticals.

Chen L, Yang B, McNulty JA, et al. Peroxisome proliferatoractivated receptor \{gamma\} agonist, changes electrolytes and water 
reabsorption from the distal nephron in rats. J. Pharmacol. Exp. Ther. 2005;312: $718-725$

Glick Z, Oshiro A and Sod-Moriah U . Effects of acarbose in rats are influenced by the type of dietary starch. Pharmacol. Biochem. Behav. 1986; 25(2):491-4.

Guan Y, Hao C, Cha DR, et al. Thiazolidinediones expand body fluid volume through PPARgamma stimulation of ENaC-mediated renal salt absorption". Nat. Med. 2005; 11: $861-866$.

Gupta NP, Solis NG, Avella ME, et al. Hypoglycaemic activity of Neuroleena lobata. J. Ethnopharmacol.1984; 10: 323-327.

Hoffmann J and Spengler M . Efficacy of 24-week monotherapy with acarbose, metformin, or placebo in dietary-treated NIDDM patients: the Essen-II Study. Am. J. Med. 1997; 103(6):483-90

Miller J . Effects of Dietary Corn on Hematological Response of Anemic Rats to Ferrous Sulfate. J. Nutr.1978; 108: 33-39.

Nesto RW, Bell D, Bonow RO, et al. Thiazolidinedione use, fluid retention, and congestive heart failure: A consensus statement from the American Heart Association and American Diabetes Association”. Circulation 2003; 108: 2941 -2948.

Pari L and Maheswari JU . Hypoglycaemic effect of Musa sapientum L. in alloxan-induced diabetic rats. J. Ethnopharmacol. 1999; $15 ; 68(1-3): 321-5$.

Rao BK, Kesavulu MM and Apparao C . Antihyperglycemic activity of Momordica cymbalaria in alloxan diabetic rats. Journal of Ethnopharmacology 2001; 78 (1): 67-71.
Saito T, Ishikawa S, Higashiyama M, et al. Inverse distribution of serum sodium and potassium in uncontrolled inpatients with diabetes mellitus. Endocr J. 1999; 46(1):75-80.

Shahid SM, Rafique $\mathrm{R}$ and Mahboob T. Electrolytes and sodium transport mechanism in diabetes mellitus. Pakistan Journal of Pharmaceutical Sciences 2005; 18(2):6-10.

Totan AR and Greaby M. Effect of chronic hyperglycemia and vanadate treatment on erythrocyte $\mathrm{Na}+\mathrm{K}+-\mathrm{ATPase}$ and $\mathrm{Mg}++-$ ATPase in streptozotocin in diabetic rats". Acta. Pol. Pharm. 2002; 59: 307-11.

Weber CR, Piacentino V, 3rd, Houser SR, and Bers DM . Dynamic regulation of sodium/calcium exchange function in human heart failure. Circulation 2003; 108: 2224-2229.

Zhang H, Zhang A, Kohan DE, et al. Collecting duct-specific deletion of peroxisome proliferator-activated receptor gamma blocks thiazolidinedione-induced fluid retention”. Proc. Natl. Acad. Sci. U S A. 2005; 102: 9406 -9411.

\section{How to cite this article:}

Humera Khatoon and Rahila Najam. Effects of Rosiglitazone and Acarbose (with and without Cornstarch Diet) on Serum Electrolytes in Diabetic Rats. . J App Pharm Sci. 2012; 2(9): 050053. 